\title{
TEACHING SELF-AWARENESS AND SELF- REGULATION TECHNIQUES TO A CHILD WITH AUTISM SPECTUM DISORDER
}

\author{
Maria Kontogianni \\ Include, Greece \\ Andromachi Nanou \\ Include, Greece
}

\begin{abstract}
Self-awareness and self-regulation yoga techniques lead to stress management, reducing anxiety and well-being of individuals with Autism Spectrum Disorders. The current study seeks to investigate the degree of the autonomous involvement of an 11-year-old girl with Autism Spectrum Disorder in the self-awareness and self-regulation yoga exercises. The research was designed as an educational intervention. The intervention was applied once a week for 3 months, and took place at the sensory room of "School for all: Tokei Maru" at Include in Thessaloniki. Research diaries and observation protocols, by participant and external observers, were used for data collection before, during and after the intervention. According to the research findings, girl's degree and quality of involvement improved during the intervention, so that she managed to use specific techniques autonomously. Research findings cannot be generalized, but they are encouraging in developing effective self-awareness and self-regulation programs for children with Autism Spectrum Disorder in future research.
\end{abstract}

Keywords: alternative therapy, ASD, autism, Self-awareness, Self-Regulation, yoga.

\section{Introduction}

As the number of children with Autism Spectrum Disorders (ASD) is increasing, researchers have been widely developed to investigate etiological factors, behavioral characteristics and effective interventions, all over the world. In strong connection with behavior problems of children with autism spectrum disorder (ASD), are self-regulation difficulties (Berkovits et al., 2017). Selfregulation is the ability to focus attention, manage emotions, and control behaviors to cope with environmental demands (Williford et al., 2013).

The ability of self-regulation develops through interactions with adults, peers, and the learning context according to Vygotsky's theory (Vygotsky, 1978). Self-Awareness is the awareness of the uniqueness of their body and mind. S-AR techniques in inclusive learning environments benefit all children and especially children with Autism Spectrum Disorder (ASD) or other Special Educational Needs (Hanapi \& Latipun, 2019). Children in ASD, as they face social and 
Kontogianni \& Nanou, 2020. Teaching Self-Awareness and Self-Regulation Techniques to a Child with Autism Spectum Disorder

behavioral dysfunction, they cannot learn self-regulation skills by social interaction, so they are expected to face Dysregulation or Self-regulation difficulties (Berkovits et al., 2017).

Approaching alternatively the development of Self-regulation and selfawareness (S-AR), an aggregation of empirical and research data focused on yoga practice (Vago \& Silbersweig, 2012). Research findings demonstrates-that, attending lessons of self-regulation and self-awareness (S-AR) through yoga, children can improve the understanding of emotions, as well as specific motor and psychosocial aspects of development (Thorton \& Hardy, 2015; Smith et al., 2020). The purpose of this study was to evaluate the degree of the autonomous participation of an 11-year old girl with ASD in S_AR techniques. The research followed the educational intervention methodology. Observing protocols from participant and an external observer were used for data collection before, after and during the educational intervention, in combination with participant researcher's diaries.

\section{Literature Review}

Yoga, is gaining popularity, as a complementary and alternative therapy for multiple reasons. Furthermore, it improves flexibility, balance and strength of mind and body (Kaur \& Bhat, 2019). It offers multisystem experiences, impacting several developing systems including motor (flexibility, strength, balance), perceptual (joint proprioception, kinesthesia) (Mohanty, Pradhan, \& Nagathna, 2014), behavioral (attention, alertness) (Jensen \& Kenny, 2014) and children's social communication skills (social interactions, speech) (Smith, Esat, \& Kanojia, 2020).

The current yoga research is encouraging for treating behavioral difficulties of children with ASD. Specifically, the use of daily yoga intervention at school has a significant impact on classroom behaviors among children with ASD (Koenig, Buckley-Reen, \& Garg, 2012). Porter found that after the participation of an 11 years old boy with ASD in yoga lessons, his attention improved (Porter, 2013). Rosenblatt found efficacy in treatment of behavioral difficulties of 24 children aged 3-16 years, with a diagnosis of ASD after 8-week multimodal yoga, dance, and music therapy program (Rosenblatt, 2011).

Based on research findings that confirm the positive effects of yoga lessons in multiple aspects of children with ASD development this study investigated the degree and the quality of the autonomous participation of one girl with ASD, in the educational intervention of Shelf-awareness and shelf -Regulated techniques. The "participation" is considered as attendance and involvement in the execution of techniques (Nyquist et al., 2019). 


\section{Research methodology}

The research methodology was qualitative and followed the educational intervention procedure. The educational intervention methodology involves the design, implementation, and evaluation of a curriculum in a particular subject and may relate to either the content or the teaching process. It requires measurements before and after the intervention in the experimental group to which the intervention is applied (Nanou, Giatrakou, \& Maistrellis, 2020). Triangulation method was used, to ensure reliability of the results in this research. This method applied, as an attempt to maintain record and study, completely, the richness and complexity of Harriet's involvement, from more than one standpoint with more than one tool of data collection (Cohen \& Manion, 2000).

Participants. In the educational intervention research participated an 11-year-old girl, Harriet, with ASD diagnosis from Public Authorities. According to the DSM_5 criteria Harriet was needed substantial support (level 2). The girl had difficulties, in speech, communication and adjustment social and environmental changes. Even though she could follow simple instructions she had difficulties communicating her needs to the others, especially to unfamiliar persons. She used simple words, but these, in most cases, was not suitable for the communication circumstances. Harriet, at the point of our intervention was not attached in specific objects and has a range of interests. She had developed writing skills and she used to draw or dance if she was asked. Her great difficulty was the management of acoustic stimuli. She used to be nervous and she had difficulties to concentrate in inclusive and noisy environment. Harriet used to participate in inclusive robotic activities with other Special Educational Needs or typical peers at "School for all: Tokei Maru". Before her participation in inclusive activities she used to enter at the sensory integration room (snoezelen room) where she used to lie on the water mattress and stay calm. When she entered in inclusive activities room Harriet closed her ears because of noise. This observation motivated the S-AR teacher to design and try to implement an S-AR program and investigate if Harriet would learn to implement specific S-AR techniques in order to stay calm. She was the chosen one to participate in self-regulation and self- awareness intervention program at Include "School for all: Tokei Maru" with her parents' consent.

Place and time. The teaching intervention implemented during the 2018-2019 academic year. In a total of 12 sessions conducted in 3 months at a once a week frequency inside the sensory integration room, with a water mattress at inclusive non-formal environment of "school for all Tokei Maru". The session lasted 45 minutes before her involvement in inclusive activities. 
Kontogianni \& Nanou, 2020. Teaching Self-Awareness and Self-Regulation Techniques to a Child with Autism Spectum Disorder

\section{Teaching Methodology}

In this educational intervention research, a traditional motif of selfawareness and a yoga session was followed by a specialized HATHA Yoga SelfAwareness and Regulated teacher (S_AR teacher). The intervention program started with two attention concentrating exercises (A.1, A.2) in order to gain the suitable attention of the practitioner. Secondly, but extremely important is the breathing exercises that are the key for a successful self-regulation session. Breathing is important for the parasympathetic nervous system and relates to the slowing of the heart rate, reducing stress conditions, and the body and mind connection-awareness (Rama, Balentie, \& Hymes, 2011). Every session involved two types of breathing. Diaphragmatic and slow and deep breathing (Thorton \& Hardy, 2015). After breathing, she continued with body exercises. Three vestibular, an intervention (B.1) and a forward bend (B.2), for regulating attention, concentration and emotional /behavioral stability. After these two, we use three proprioceptive exercises, two for stretching (B.3, B.4) and one for the joint compression (B.5), so that the practitioner feels her space in the room, grounding and better body coordination (Thorton \& Hardy, 2015). The last exercises are two balancing poses (C.1, C.2) which improves memory and concentration and is connected with the part of the brain which controls the body in motion. The last part of the session is the two relaxation techniques which includes a slow breathing technique (D.1) and sitting or lying down in a comfortable pose, supported with sensory stimuli props ,like a water mattress , heavy and soft blankets etc.(D.2). In these positions we might follow a guided meditation, depended on the circumstances. Meditation is a conscious process of self-regulation that tempers the flow of thoughts, emotions, and automatic behaviors in the body and mind according to a research. (Sequeira \& Ahmed, 2012).

\section{Data collection}

To achieve the purpose of the educational intervention were designed and implemented specific data collection tools. Particular tools, depending on the needs of each teaching intervention, have been designed and implemented in other teaching interventions (Nanou et al., 2020). The S_AR rating scale was used to assess the Harriet's autonomous involvement-participation before, during and after the intervention in every exercise in every session (Figure 1). Participation is determined as involvement, motivation, perseverance, interaction, and influence (Imms et al., 2017). S_AR rating scale is an adaptation of a corresponding scale which was used to detect the participation of SEN children in kindergarten activities (Varsamis et al., 2018) and in the assessment of children 
with ASD participation in Judo activities (Nanou et al., 2020). In S_AR rating scale, 1 to 6 point was used to assess the participation in accordance of the S-AR teacher's support. More specifically point $1=$ no involvement, 2 = early-level involvement with support $3=$ autonomous early-level involvement, $4=$ satisfactory involvement with support, $5=$ autonomous satisfactory involvement, 6 = excellent autonomous involvement. Researcher's diaries were used by the S-AR teacher after every session where recorded researcher's observation for feedback and reorganization of educational intervention. An external observer, special Pedagogue asses Harriet's participation with the same S-AR Rating scale before, in the middle and after participation $\left(1^{\text {st }}, 6^{\text {th }}\right.$ and $12^{\text {th }}$ session $)$.

\section{Findings}

In the first two sessions, according to research diaries of S-AR teacher, Harriet shown that she tried to fill comfortable with the new demands in the Snoezelen room. She was asked to imitate her teacher but Harriet did not respond. "She cannot understand that she has to imitate me". The teacher observed that despite there was an optical stimulus of the exercises, Harriet had difficulties with the attention, proprioceptive exercises and the guided meditation. She confronted difficulties with the position of her body in the sensory room. The teacher used physical guidance to help her participation. According to the S-AR scale her involvement was assessed with 1 or 2. Oppositely, Harriet in breathing exercises had a great success of participation without the intervention-physical guidance of the teacher. Breathing calmed the nervous system and helped the participant be more aware of her space in the room (sensory integration). According to the SAR scale her involvement was assessed with 3 which mean that Harriet involved in S-AR in base level without the physical guidance of S-AR teacher.

In the third, fourth and fifth session, Harriet showed to get improved not only in the breathing techniques but also in the body exercises. As is shown in the 12- session assessment, the teacher could get easier Harriet's attention with a small, or no intervention - physical guidance because she started trust the teacher According to the S-AR scale her involvement was assessed with 3 to 5 . The breathing exercises in the beginning and at the end of the session had an impressive development. Harriet shown at the begging of all sessions that was impressed by the sound of her breath and it was very pleasant for her to copy the techniques. According to the S-AR scale her involvement was assessed with 5 to 6 fir.1). The exercises needed the guidance of the teacher because they were complicated and new for the participant but at the meditation Harriet seemed to feel very comfortable and stay for more time without the guidance of the teacher (fir.1, 4th, 5th, 6th session). As S-AR teacher notes in her research diary "She follows easier the body exercises, but most importantly she follows the breathing 
Kontogianni \& Nanou, 2020. Teaching Self-Awareness and Self-Regulation Techniques to a Child with Autism Spectum Disorder

and relaxing techniques, which are related with the concentration, without any help from the teacher. She has just improved her mimetic skills so good that her mind has already embraced the session path in her routine".

From the sixth to the eighth session, the teacher was there just to demonstrate to Harriet the sequence of the exercises, because she was already used to them. Harriet needed some guidance only in some proprioceptive exercises that are more difficult than the other exercises and with the balance exercises, for the same reasons. From the ninth to the twelfth session the development of Harriet was remarkable, because apart from the fact that she participated in all the stages of the session without the intervention of the teacher, she also manifested her own suggestions and inspirations in breathing and in some exercises. The most important in the twelfth session, and the point that the teacher considered as the great success of all the research, is the meditation exercises. Harriet managed to stay laid on the water mattress until the teacher said that the session was over, and she had to get up. She was very calm and happy and from that time she looks for the meditation time in every session. According to the S-AR scale her involvement was assessed with 5 to 6 (table 1). As S-AR teacher notes in her research diary "Harriet is ready to follow the session, easy and she can feel the benefits. She stays calmer and she gets very fast in a deep concentration mood".

Table 1 Table of S-AR points of Harriet's involvement during 12 week sessions

\begin{tabular}{|c|c|c|c|c|c|c|c|c|c|c|c|c|c|}
\hline \multicolumn{2}{|c|}{ S_AR exercises } & 10 & 20 & 30 & 40 & 50 & 60 & 70 & 80 & 90 & 100 & 110 & 120 \\
\hline \multicolumn{2}{|l|}{$\begin{array}{l}\text { Attention } \\
\text { A. } 1\end{array}$} & 1 & 1 & 2 & 2 & 4 & 4 & 5 & 5 & 6 & 6 & 6 & 6 \\
\hline \multicolumn{2}{|l|}{$\begin{array}{l}\text { Breathing } \\
\text { A. } 2\end{array}$} & 3 & 3 & 5 & 5 & 5 & 6 & 6 & 6 & 6 & 6 & 6 & 6 \\
\hline \multirow[t]{2}{*}{ Body exercise } & B.1 & 2 & 3 & 4 & 3 & 3 & 4 & 5 & 5 & 5 & 5 & 5 & 5 \\
\hline & B. 2 & 3 & 3 & 3 & 3 & 3 & 3 & 4 & 4 & 5 & 5 & 5 & 6 \\
\hline \multirow{3}{*}{$\begin{array}{l}\text { Proprioceptive } \\
\text { exercises }\end{array}$} & B.3 & 2 & 2 & 2 & 3 & 3 & 3 & 4 & 4 & 4 & 5 & 5 & 5 \\
\hline & B. 4 & 3 & 3 & 4 & 4 & 5 & 5 & 5 & 5 & 5 & 6 & 6 & 6 \\
\hline & B.5 & 1 & 1 & 2 & 3 & 5 & 5 & 5 & 5 & 5 & 5 & 5 & 6 \\
\hline \multirow[t]{2}{*}{ Balancing poses } & C.1 & 3 & 4 & 5 & 5 & 5 & 5 & 5 & 5 & 5 & 5 & 5 & 5 \\
\hline & C. 2 & 1 & 3 & 3 & 3 & 3 & 3 & 5 & 5 & 5 & 5 & 5 & 5 \\
\hline \multicolumn{2}{|l|}{$\begin{array}{l}\text { Slow breathing } \\
\text { D.1 }\end{array}$} & 2 & 2 & 3 & 4 & 4 & 5 & 5 & 5 & 6 & 6 & 6 & 6 \\
\hline \multicolumn{2}{|c|}{$\begin{array}{l}\text { Guided meditation } \\
\text { D.2 }\end{array}$} & 1 & 2 & 2 & 4 & 4 & 5 & 5 & 6 & 6 & 6 & 6 & 6 \\
\hline \multicolumn{2}{|l|}{ AVERAGE } & 2 & 2,5 & 3,2 & 3,5 & 4 & 4,4 & 4,9 & 5 & 5,3 & 5,5 & 5,5 & 5,6 \\
\hline
\end{tabular}

In S-AR teacher notes from her research diary, at the 10nth session "Harriet participates in the session almost 100 percent, she remembers the steps of the session, she does the exercises very easy. Moreover she is creative in the exercises 
and makes her own, but in harmony, moves" As the participant R-AR teacher notes in her diary, Harriet's involvement was gradually became autonomous but the most important of all is that in the $12^{\text {th }}$ session the child managed to remain on a lying position with the eyes closed for 10 minutes and with open eyes for more than 20 minutes.

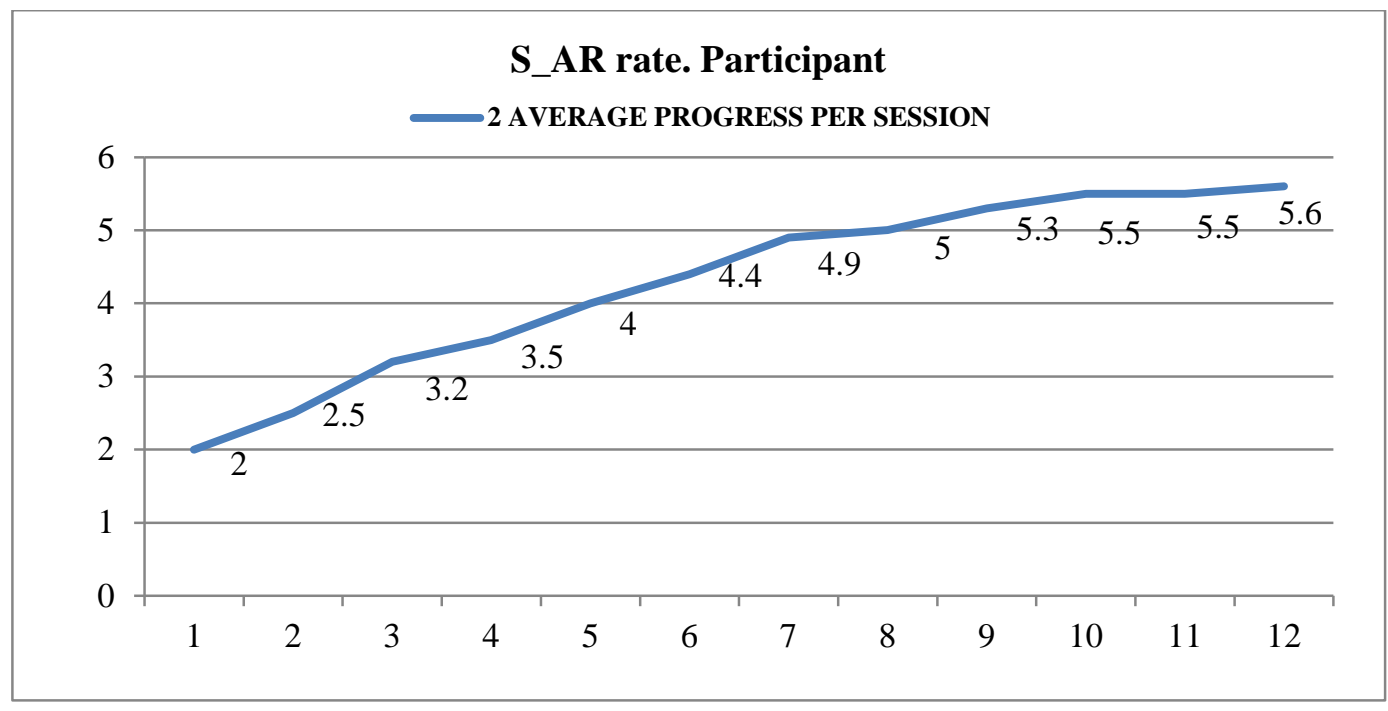

Figure 1 Mean of child's involvement in S-AR exercises in 12 sessions

In Figure 1 the mean points of Harriet's involvement in S-AR exercises during the 12 session intervention, are presented. Her average involvement was improved from 1rts session to 12th session. The findings indicate that at the 1rst session Harriet participated in the S-AR exercises with the teacher's support (2 points) but after 12 sessions managed to be autonomous (5, 6 points).

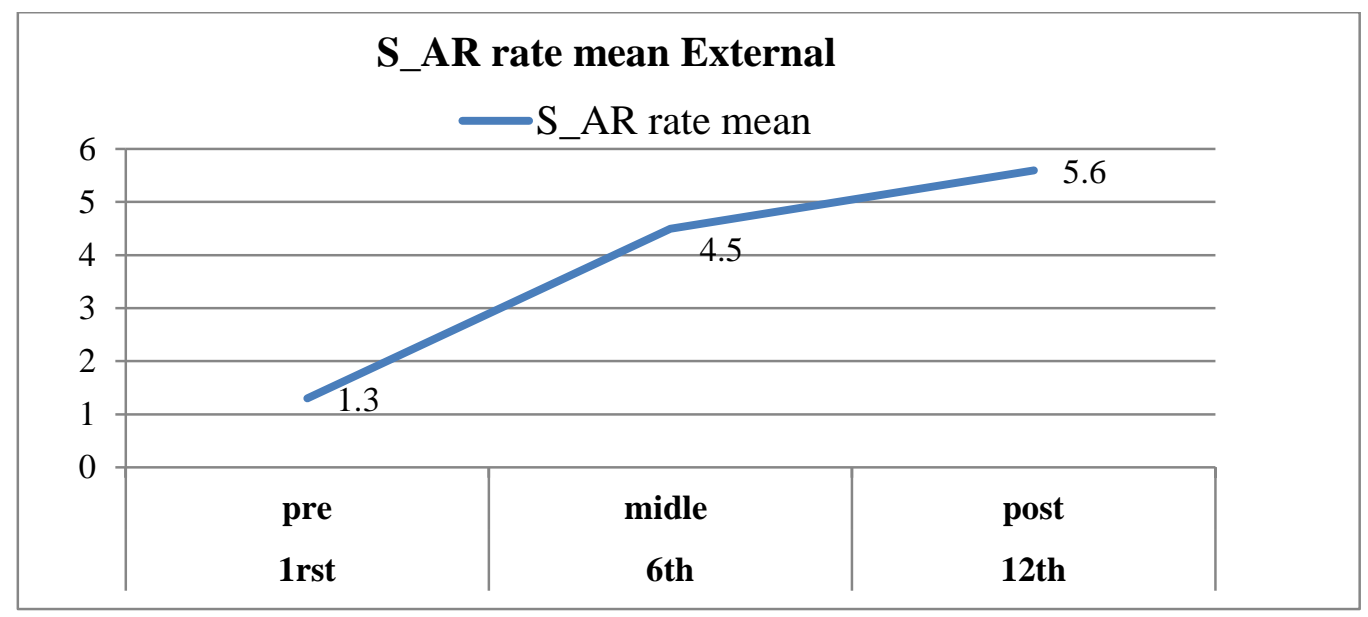

Figure 2 Assessment of the Involvement of the child in every session from external observers point if view 
Kontogianni \& Nanou, 2020. Teaching Self-Awareness and Self-Regulation Techniques to a Child with Autism Spectum Disorder

Similar findings emerged from the assessment of Harriet's involvement by the external observer (Figure 2). The external observer assessed Harriet's involvement in S_AR exercises at the pre-1 ${ }^{\text {st }}$, middle -6th, and post-12th sessions. At the 1st session, Harriet's involvement assessed with 1,5 at the 4th session with 4,5 and at the 12th session with 5,6. These findings demonstrate that Harriet improved her involvement in S-AR exercises gradually. At the 12th session according to the external observer, Harriet participated independently without the support of her teacher $(5,6)$. The external observer's assessment confirms the assessment of S-AR teacher and her observations as they were recorded in S-AR teacher's diaries (Figure 3).

\section{Conclusions}

According to the findings, Harriet improved her participation, gradually, during the intervention. She learned the sequencing of S-R and S-A alternative techniques, but moreover she remained in a relaxed position and began to improvise for more than twenty minutes. Her involvement gradually became autonomous. She could follow the steps of the Self-awareness and Self-regulation exercises, and moreover she was creative on how she executed them. Although the educational intervention was implemented in one subject and the findings cannot be generalized, they are encouraging. Autonomous participation of children with disabilities in every aspect of social and educational activities is a prerequisite of self-determination (Imms et al., 2017). Future research should focus on the type of S-AR exercises that a child with ASD could follow autonomously, in order to learn how to be focused, to manage emotions, and to control behaviors in order to cope with environmental demands. Self -regulation and awareness programs are of great importance to be developed for children with Autism Spectrum disorder and other behavioral difficulties.

\section{References}

Berkovits, L. (2016). Emotion regulation in young children with autism spectrum disorder. J Autism Dev Disord., 47, 68-79

Cohen, L., \& Manion, L. (2000). Research methods in education. 254. (5th edition). Rutledge. Garfinkel, MS1., Singhal, A., Katz, W.A., Allan, D.A., Reshetar, R., \& Schumacher, H.R. Jr. (1998). Yoga-based intervention for carpal tunnel syndrome: a randomized trial. JAMA, 280(18), 1601-3.

Hanapi, Trie, Nurfadillah, \& Latipun. (2019) Interventions Using Individual and Social Approaches (Non-Medication) in Improving the Self-Regulation of Children with Special Needs and Self-Regulatory Problems DOI: https://dx.doi.org/10.2991/assehr.k. 200120.052

Imms, C., Granlund, M., Wilson, P.H., Steenbergen, B., Rosenbaum, P.L., \& Gordon, A.M. (2017). 'Participation': Participation, both a means and an end: a conceptual analysis of processes and outcomes in childhood disability, 59(1), 16-25. Retrieved from https://onlinelibrary.wiley.com/doi/full/10.1111/dmcn.13237 
Kaur, M., \& Bhat, A. (2019). Creative Yoga Intervention Improves Motor and Imitation Skills of Children with Autism Spectrum Disorder. Physical Therapy, 99, 11, 1520-1534. DOI: https://doi.org/10.1093/ptj/pzz115

Koenig, KP1., Buckley-Reen, A., \& Garg, S. (2012). Efficacy of the Get Ready to Learn yoga program among children with autism spectrum disorders: A pretest-posttest control group design. Am J Occup Ther., 66(5), 538-546. DOI: 10.5014/ajot.2012.004390.

Kopp, Claire, B. (1989). Regulation of distress and negative emotions: A developmental view. Developmental Psychology, 25(3), 343-354.

Nanou, A., Giatrakou, A., \& Maistrellis, A. (2020). Learn how to fall to stand up and demand: An inclusive educational program on basic judo techniques for children with autism. GRAFIMA Thessaloniki

Nyquist, A., Jahnsen, R.B., Moser, Th., \& Ullenhag, A. (2019). The coolest I know - a qualitative study exploring the participation experiences of children with disabilities in an adapted physical activities program, Disability and Rehabilitation. DOI: https://doi.org/10.1080/09638288.2019.1573937

Polsgrove, M.J., Eggleston, B.M., \& Lockyer, R.J. (2016). Impact of 10-weeks of yoga practice on flexibility and balance of college athletes. International journal of yoga, 9(1), 27-34.

Porter, J. (2013). Yoga as an Effective Behavioral Intervention for Children Diagnosed with an Autism Spectrum Disorder. Graduate Annual, 1(9). Retrieved from https://digitalcommons.lasalle.edu/graduateannual/vol1/iss1/9

Rama, S., Balentine, R., \& Hymes, A. (2011). Science of Breath: A Practical Guide. Honesdale. PA Himalayan Institute of Yoga Science and Philosophy of the USA

Rosenblatt, E.L., Sasikanth, G.J., Torres, A., Yarmush, R.S., Rao, S., Park, E.R., Denninger, J.W., Benson, H., Fricchione, G.L., Bernstein, B., \& Levine, B.J. (2011). Relaxation Response-Based Yoga Improves Functioning in Young Children with Autism: A Pilot Study. DOI https://doi.org/10.1089/acm.2010.0834

Siegel, D.J. (1999). The developing mind: Toward a neurobiology of interpersonal experience. New York: Guilford Press.

Smith, B.H., Esat, G., \& Kanojia, A. (2020). School-based yoga for managing stress and anxiety. In C. Maykel \& M.A. Bray (Eds.), Applying psychology in the schools. Promoting mind-body health in schools: Interventions for mental health professionals (pp. 201-216). American Psychological Association. DOI: https://doi.org/10.1037/ 0000157-014

Thorton, H.S. (2015). Asanas for Autism and Special Needs: Breathing and Breath Awareness 45., Self-Regulation and Body Awareness, 153-154.

Vago, D.R., \& Silbersweig, D.A. (2012). Self-awareness, self-regulation, and selftranscendence (S-ART): A framework for understanding the neurobiological mechanisms of mindfulness. Front. Hum. Neurosci., DOI: https://doi.org/10.3389/fnhum.2012.00296

Varsamis, P., Gkouvatzi, A., Nanou, A., Ntarilli, I., \& Simeonidou, M. (2018). Preschool Curriculum-based Screening for Pre-referral Support. Twenty-third International Conferences on Learning Virtual Poster L18P300. Athens, Greece, 21-23 June.

Vygotsky, L.S. (1978). Mind in society: The development of higher psychological processes. Cambridge, MA: Harvard University Press.

Williford, A., Jessica, E., Whittaker, V., Vitiello, V., \& Downer, J. (2013). Children's Engagement within the Preschool Classroom and Their Development of Self-Regulation.

Early Education and Development, 24(2), 162-187. DOI: 10.1080/10409289. 2011.628270 